\title{
Anti-Müllerian hormone overexpression restricts preantral ovarian follicle survival
}

\author{
Michael W Pankhurst', Rebecca L Kelley², Rachel L Sanders', Savana R Woodcock', Dorothy E Oorschot ${ }^{1,3}$ and \\ Nicola J Batchelor ${ }^{1}$
}

'Department of Anatomy, School of Biomedical Sciences, University of Otago, Dunedin, New Zealand

2School of Biosciences, University of Melbourne, Melbourne, Australia

${ }^{3}$ Brain Health Research Centre, University of Otago, Dunedin, New Zealand

Correspondence should be addressed to M W Pankhurst: michael.pankhurst@otago.ac.nz

\section{Abstract}

Anti-Müllerian hormone $(\mathrm{AMH})$ is an ovarian regulator that affects folliculogenesis. $\mathrm{AMH}$ inhibits the developmental activation of the dormant primordial follicles and the oocyte within. In more mature follicles, $\mathrm{AMH}$ reduces granulosa cell sensitivity to folliclestimulating hormone (FSH). We examined the effects of $\mathrm{AMH}$ overexpression on the stages of ovarian folliculogenesis, and the development of embryos, with a transgenic mouse that overexpresses human $\mathrm{AMH}$ in central nervous system neurons under the control of the mouse Thy1.2 promoter (Thy1.2-AMH'g mice). These mice are severely sub-fertile, despite relatively normal ovulation rates. The embryos of Thy1.2-AMH'g females exhibited delayed preimplantation development and extensive mid-gestation fetal resorption. Young Thy1.2- $A M H^{\top \mathrm{Tg}}$ mouse ovaries exhibited only a slight reduction in the rate of primordial follicle activation but large declines in the number of developing follicles surviving past the primary stage. It was expected that Thy1.2-AMH ${ }^{\top 9}$ mice would retain more primordial follicles as they aged, but at 5 months, their number was significantly reduced relative to wild-type females. These data indicate that moderate elevations in $\mathrm{AMH}$ levels can severely restrict reproductive output and the number of developing follicles in the ovary. This evidence suggests that early antral follicles are a target for AMH signaling, which may regulate early follicle survival.

\author{
Key Words \\ - anti-Müllerian hormone \\ - ovary \\ - folliculogenesis \\ - oogenesis \\ - embryo
}

\section{Introduction}

Mammalian ovaries are endowed with a finite number of oocytes during early development. The dormant oocytes are encapsulated by pre-granulosa cells in structures known as primordial follicles. Primordial follicles are released from dormancy during activation, which is the initial stage of folliculogenesis. The rate of activation determines the size of the developing follicle pool and the lifetime of the ovarian reserve of primordial follicles (Faddy et al. 1992, Depmann et al. 2015). The developing follicle pool contains more oocytes than are required for ovulation. The excess follicles undergo a degenerative process known as atresia leaving only a fraction to be selected for ovulation (Monniaux et al. 2014).

Anti-Müllerian hormone $(\mathrm{AMH})$ is produced by granulosa cells within developing follicles and regulates ovarian reserve depletion by inhibiting primordial follicle activation (Durlinger et al. 1999, 2002, Carlsson et al. 2006). The activation of primordial follicles leads to transition to the primary stage. Subsequent progression through the preantral stages is facilitated by oocyte growth and 
proliferation of the associated granulosa and theca cells. The antral stages are characterized by the acquisition of a fluid-filled cavity and an increasing reliance on pituitaryderived follicle-stimulating hormone (FSH) for survival (McGee \& Hsueh 2000). AMH expression peaks at the small antral stage (Weenen et al. 2004) and the ability of AMH to counteract the effects of FSH (Visser \& Themmen 2014) suggests these follicles are an AMH signaling target. Larger, preovulatory follicles are unlikely to be influenced by $\mathrm{AMH}$ due to reduced expression of AMH and its type 2 receptor, AMHR2 (Baarends et al. 1995, Weenen et al. 2004).

$A m h^{-1-}$ mice have increased rates of primordial follicle activation, increased numbers of developing follicles and accelerated depletion of the ovarian reserve (Durlinger et al. 1999). However, atresia is proportionately increased in $\mathrm{Amh}^{-1-}$ mice and the number of preovulatory follicles available at the time of ovulation is not different to $\mathrm{Amh}^{+/+}$mice (Visser et al. 2007). This suggests that AMH has strong effects on primordial follicle activation but is less important in the regulation of follicles at later stages of development. However, experimental reduction in AMH levels in rhesus macaques can cause an increase in the number of eggs ovulated (Xu et al. 2016), indicating that $\mathrm{AMH}$ can influence the later stages of folliculogenesis in some circumstances.

This study describes the ovarian phenotype in a transgenic AMH-overexpressing (Thy1.2-AMH $H^{\mathrm{Tg}}$ ) mouse model with AMH overexpression that was originally created to examine the effects of $\mathrm{AMH}$ in the brain (McLennan et al. 2017). The Thy1.2-AMH ${ }^{\mathrm{Tg}}$ mice express a human AMH transgene under the murine Thy1.2 gene promoter, which is active in a large proportion of central nervous system neurons. Adult Thy1.2-AMH ${ }^{\mathrm{Tg}}$ mice have circulating AMH levels at approximately $1 \mathrm{nmol} / \mathrm{L}$ (McLennan et al. 2017) and the endogenous murine proteases are capable of converting the inactive AMH proprotein into the cleaved, receptor-binding isoform $\left(\mathrm{AMH}_{\mathrm{N}, \mathrm{C}}\right)$ (Pankhurst et al. 2016). The elimination of $\mathrm{AMH}_{\mathrm{N}, \mathrm{C}}$ is biphasic with a fast-phase that is consistent with rapid dispersal into interstitial fluid (Pankhurst et al. 2016), suggesting that tissue and circulating AMH concentrations reach equilibrium. For context, circulating AMH levels are $\sim 200 \mathrm{pmol} / \mathrm{L}$ in wild-type female mice (Kevenaar et al. 2006) and follicular fluid AMH concentrations in humans can be as high as $6.4 \mathrm{nmol} / \mathrm{L}$ (Jeppesen et al. 2013). In the present study, Thy1.2-AMH $H^{\mathrm{Tg}}$ females were found to be severely sub-fertile, with evidence of abnormal preimplantation embryo development. Primordial follicle activation was modestly reduced but a large reduction in the preantral follicle population suggests that preantral follicles are more susceptible to the effects of elevated AMH concentrations than previously thought.

\section{Materials and methods}

\section{Animals}

The Thy1.2-AMH transgenic mice express a human AMH transgene in central nervous system neurons in multiple brain nuclei under the control of the murine Thy1.2 gene promoter, beginning at approximately 21 days of age (McLennan et al. 2017). Breeding colonies were maintained on a C57B16/J background with wild-type females (Thy1.2-AMH ${ }^{\circ / 0}$ ) paired to hemizygous transgenic males (Thy1.2-AMH $\left.{ }^{\mathrm{Tg} / 0}\right)$. Experimental females were Thy1.2- $A M H^{0 / 0}$ (wild type) and Thy1.2-AMH ${ }^{\mathrm{Tg} / 0}$ (denoted as Thy1.2-AMH ${ }^{\mathrm{Tg}}$ ) litter mates derived from these pairings. All stud males used in the experiments had wild-type genotypes (Thy1.2- $A M H^{0 / 0}$ ) unless otherwise mentioned. Genotypes were determined by PCR using primers directed to the Thy1.2 promoter region ( $5^{\prime}$-TGT AGC TTT CCC CAC CAC AGA-3') and the human $A M H$ transgene (5'-AGG GCC TCA GTC CCC AGC AGA-3'). The mice were housed with access to food and water, ad libitum under 12:12 light-darkness cycles. All experiments were approved by the University of Otago Animal Ethics Committee or the University of Melbourne Animal Ethics Committee.

\section{Mid-gestation fetal survival}

Thy1.2-AMH ${ }^{\mathrm{Tg}}$ and wild-type female mice were mated with wild-type studs and the females were examined daily, $2 \mathrm{~h}$ after the onset of the light phase. Embryonic day 0 (E0) was recorded when a copulatory plug was observed. The females were euthanized at E10 and the uteri were examined for the presence of growing feto-placental units. Fetuses were categorized as unhealthy if they were hemorrhagic, had lost turgor or were overtly small relative to their adjacent fetuses.

\section{Preimplantation embryo examination}

Thy1.2-AMH ${ }^{\mathrm{Tg}}$ and wild-type female mice were housed in an animal house with a shifted light cycle. Females were paired with wild-type studs $8 \mathrm{~h}$ after the onset of the darkness phase for a period of $2 \mathrm{~h}$. The female mice were then removed from the stud-cage and examined 
for the presence of a copulatory plug. The process was repeated until the female became pregnant. The mated females were killed 74-76h after copulation and the embryos were flushed from the uteri with Hanks balanced salt solution (ThermoFisher Scientific, cat\# 14175-095) driven through a 27 gauge needle attached to a $1 \mathrm{~mL}$ syringe. Embryos were examined under a phase-contrast microscope to record the stage of development according to previously established criteria (Kaufman 1992). A morphological abnormality was recorded if embryos exhibited asymmetric cell division cellular degeneration/ fragmentation or failure to progress beyond the 8-cell stage. Single (uncleaved) cells within the zona pellucida were recorded as unfertilized oocytes/arrested zygotes as it was not possible to distinguish between the two.

\section{Preimplantation embryo culture}

Embryos were obtained from 25-day-old C57BL/6 $\times$ CBA F1 hybrid mice, which were superovulated with 5 IU pregnant mare serum gonadotropin (Folligon; MSD Animal Health, Bendigo East, Australia), IP at the mid-point of the light phase. $5 \mathrm{IU}$ human chorionic gonadotropin (hCG) (Chorulon; MSD Animal Health) was administered $48 \mathrm{~h}$ later and the female was paired with a C57BL/6×CBA F1 stud male. The mated females were killed 22 hours after hCG injection, embryos were dissected from the oviducts and prepared for culture as described previously (Gardner \& Lane 2007, 2014). Pronucleate oocytes were pooled and allocated randomly to the culture treatments. Single embryos were cultured in $2 \mu \mathrm{L}$ G1 medium (Vitrolife, Göteborg, Sweden) under paraffin oil (Ovoil; Vitrolife) in a humidified multi-gas incubator at $37^{\circ} \mathrm{C}$ with $5 \% \mathrm{O}_{2}$ and $6 \% \mathrm{CO}_{2}$. Embryos were cultured in media containing $0 \mathrm{pmol} / \mathrm{L}$ (control), 20, 200 or $2000 \mathrm{pmol} / \mathrm{L}$ of the $25 \mathrm{kDa}$ recombinant human AMH C-terminal fragment $\left(\mathrm{AMH}_{\mathrm{C}}\right.$, R\&D systems, cat\# 1737-MS). The treatment media was replaced after $24 \mathrm{~h}$ of culture and again at $48 \mathrm{~h}$ when the media was changed to G2 (Vitrolife). Embryo development was assessed at embryonic days 1.5 and 2.5, and afternoon of day 3.5 of culture ( 46,70 and $98 \mathrm{~h}$ post hCG).

\section{Oviduct mRNA reverse-transcriptase qPCR}

Thy1.2-AMH ${ }^{\mathrm{Tg}}$ and wild-type female mice were paired with wild-type studs $8 \mathrm{~h}$ after the onset of the dark phase of the light cycle for a period of $2 \mathrm{~h}$. Females were then checked for copulatory plugs and were killed $35-37 \mathrm{~h}$ after copulation at a time point $1 \mathrm{~h}$ before the onset of the dark phase (concurrent with the diurnal prolactin peak). A blood sample was obtained by cardiac puncture in mice anesthetized with $225 \mathrm{mg} / \mathrm{kg}$ Ketamine (Phoenix Pharm, Auckland, New Zealand) and $3 \mathrm{mg} / \mathrm{kg}$ Domitor (Medetomidine, Pfizer Animal Health, Auckland, New Zealand), and the oviducts were dissected out and incubated in RNA later (ThermoFisher Scientific, cat\# AM7020). Oviducts were frozen and stored at $-80^{\circ} \mathrm{C}$ before they were homogenized in TRI reagent (SigmaAldrich) to isolate the RNA. $1 \mu \mathrm{g}$ of mRNA was treated with 2 units of DNase (TurboDNase, ThermoFisher Scientific, cat\# AM2238) for $30 \mathrm{~min}$ at $37^{\circ} \mathrm{C}$ followed by inactivation at $75^{\circ} \mathrm{C}$ for $5 \mathrm{~min}$. RNA was converted to cDNA with the Revertaid reverse-transcription kit (ThermoFisher Scientific, cat\# K1622) using random hexamer primers. The qPCR was conducted with a LightCycler480 (Roche) cycling through $95^{\circ} \mathrm{C}$ for $20 \mathrm{~s}, 60^{\circ} \mathrm{C}$ for $20 \mathrm{~s}$ and $72^{\circ} \mathrm{C}$ for $30 \mathrm{~s}$, and then data acquisition was done. Relative mRNA expression of each transcript was calculated according to the formula $2-\Delta C_{\mathrm{p}}$ with $\beta$-actin (Actb) used as the reference gene.

\section{Prolactin assays}

Heparinized plasma samples were collected during the oviduct mRNA qPCR experiments (above). Prolactin was assayed according to a previously published procedure (Brown et al. 2010). The primary antibody (NIDKK-rabbit anti-oPRL-2, NIH, batch\# AFP131078) was used at a final concentration of 1:400,000. A mouse prolactin standard (NIDDK-mouse PRL, batch\# AFP6476C) was used to generate the standard curve and was labeled with ${ }^{125}$ I via the chloramine-T method. Iodine-labeled prolactin was added to each tube at $20,000 \mathrm{cpm}$ followed by $24-\mathrm{h}$ incubation at room temperature. The antibodies were precipitated with $5 \%$ polyethylene glycol and the radioactivity of the pellet counted and prolactin concentrations were interpolated from the standard curve.

\section{Estrous cycling}

Female mice were introduced to a cage containing soiled bedding from a male mouse cage to provide male pheromones. Vaginal lavage fluid ( $5 \mu \mathrm{L}$ of water) was collected daily and dried onto a microscope slide. Slides were stained with toluidine blue and estrus stages were determined by vaginal cytology. Proestrus was characterized by clumps of epithelial cells with sparsity of cornified epithelial cells. Estrus was characterized by a predominance of cornfield epithelial cells and proportionately fewer non-cornified cells. Metestrus and 
diestrus were analyzed together and represent the only two stages with an abundance of polymorphonuclear leukocytes present. Estrus cycles were tracked across three proestrus stages to determine the length of 2 cycles per mouse. Monitoring was ceased after 16 days if 2 cycles had not been recorded.

\section{Ovarian follicle stereological counts}

Ovarian tissue was obtained at the proestrus stage of the estrous cycle. A younger age-group was collected between 45 and 58 days of age and an older group at 150-162 days. Ovaries were dissected from the mice and immersion-fixed in Bouins fixative for $4 \mathrm{~h}$ at room temperature. The tissue was embedded in paraffin wax and serially sectioned at $5 \mu \mathrm{m}$ and stained with hematoxylin and eosin. Ovarian follicles were counted with methods adapted from Myers et al. (2004). Every follicle from the secondary stage onwards was counted by sampling serial sections at $25 \mu \mathrm{m}$ intervals in both ovaries. Preantral follicles included secondary follicles, with at least 2 layers of granulosa cells at any part of the follicle perimeter. Follicles were considered as antral if a cavity was observed at any point in the granulosa cell layer. A follicle was considered to be preovulatory if it had a diameter greater than $250 \mu \mathrm{m}$. Follicles with oocytes lacking a continuous cumulus granulosa cell layer adjacent to the oocyte were considered to be overtly atretic and were not included in counts. Primordial follicles were counted in a single ovary from each mouse by physical dissector stereology using every 10th section as the reference section and every 11th section as the look-up section. Primary follicles were counted with every 10th section used as the reference section and every 12th section used as the look-up section. Primordial follicles were counted across the entire ovary section if the nucleus was present in the reference section but not in the look-up section. Primary follicles were counted if the cytoplasm was visible in the reference section but not in the look-up section. A follicle was considered to be primordial if all granulosa cells in the reference section displayed flattened/squamous morphology. The presence of a single cuboidal granulosa cell was an indication that the follicle had begun the process of activation; hence, the follicle was counted as a primary follicle. Formulae for stereological counts are listed in (Oorschot 1994). Section area was determined using the Gaussian blur (pixel radius $=20.0$ ) and color thresholding functions of ImageJ software (NIH) to identify and measure the area within the section boundary. Cell counting was conducted with the observer blinded to the genotype.

\section{Statistical analysis}

Statistical analysis was carried out with SPSS 24.0 (IBM) and Prism 7.0 (Graphpad Software). Student's $t$-test was used to compare means between the wild-type and Thy1.2-AMH ${ }^{\mathrm{Tg}}$ females with Levene's test used to determine homogeneity of variances. One-way ANOVA was used for comparisons of three or more groups. Proportional data (percentages) were analyzed with Fisher's exact test. All data except proportional data are expressed as means \pm S.E.M.

\section{Results}

Prior investigation into the Thy1.2-AMH ${ }^{\mathrm{Tg}}$ mice revealed that the transgenic females rarely give birth when paired with males and in the rare occasions that the females gave birth, the litter size was less than half of the mean for wildtype dams (McLennan et al. 2017). The murine analogue of miscarriage is typically embryo resorption, which allows removal of nonviable fetuses without affecting viable fetuses. Fetal resorption was apparent in both wildtype and Thy1.2-AMH Ts females at embryonic day 10 (E10) (Fig. 1A and B). The prevalence of resorbing fetuses was increased relative to wild-type females (Fig. 1C), but no differences in the number of oocytes was observed on the day of ovulation (Fig. 1D). The mean ( \pm S.E.M., $n=6$ ) number of healthy fetuses remaining in Thy1.2-AMH ${ }^{\mathrm{Tg}}$ females was $4.3 \pm 1.4$. By contrast, wild-type females had an average of $10.3 \pm 1.9$ healthy fetuses at E10. Fetal resorption does not appear to be caused by expression of the transgene within the fetus because stud Thy1.2-AMH ${ }^{\mathrm{Tg}}$ males sire litters with the expected 1:1 Mendelian ratios when paired with wild-type females (Fig. 1E). Furthermore, the survival of fetuses sired by Thy1.2-AMH ${ }^{\mathrm{Tg}}$ males is not influenced by fetal sex (Fig. 1F). Collectively, this suggests that AMH overexpression has a maternal effect that reduces survival of the female's fetuses.

Fetal miscarriage can arise due to oocyte defects present prior to fertilization and in preimplantation embryos (Richardson et al. 1987). The development of preimplantation embryos of wild-type and Thy1.2-AMH ${ }^{\mathrm{Tg}}$ females was examined 74-76 h after mating (Fig. 2A, B, C, $\mathrm{D}, \mathrm{E}$ and $\mathrm{F}$ ). In this experiment, the number of embryos and unfertilized oocytes/arrested zygotes was reduced in some Thy1.2-AMH ${ }^{\mathrm{Tg}}$ females but others had counts that were equivalent to their wild-type counterparts (Fig. 2G). We have previously shown that Thy1.2- $A M H^{\mathrm{Tg}}$ females rarely give birth after mating (McLennan et al. 2017), but the present data suggest that failure to ovulate is not the cause. 

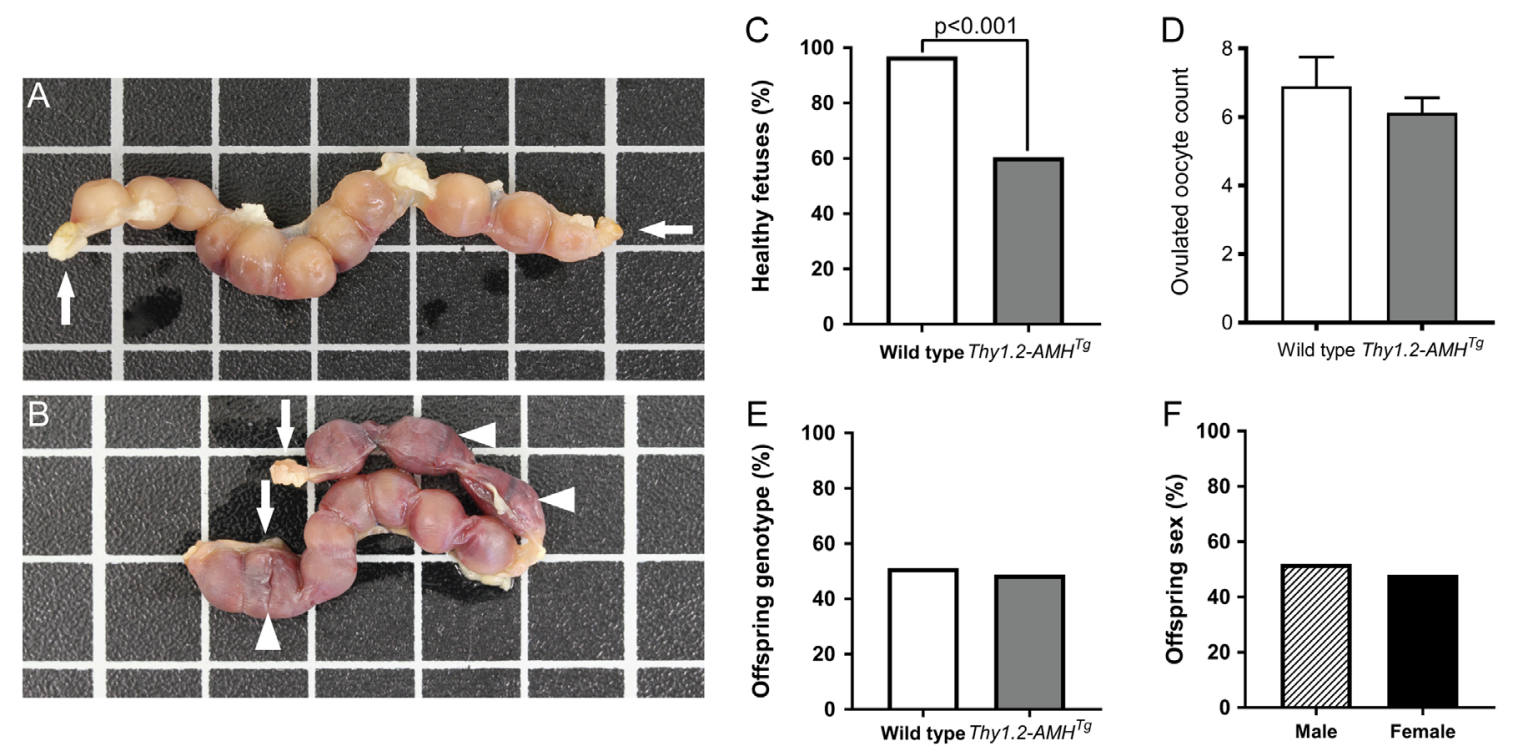

Figure 1

Thy1.2-AMH $H^{\top \mathrm{g}}$ dam uteri exhibit signs of embryo resorption at mid-gestation. The reproductive tracts of pregnant wild-type (A) and Thy1.2-AMH' (B) dams at embryonic day 10 (E10) both contain fetuses but Thy1.2-AMH'g dams more frequently exhibited signs of fetal resorption (arrowheads). The location of the ovaries are indicated by arrows, grid scale $=1 \mathrm{~cm}$. The percentage of fetuses at E10 that appeared healthy and showed no overt signs of degeneration (C) was lower in Thy1.2-AMH'T dams $(n=43)$ compared to wild-type dams ( $n=64$, Fisher's exact test). There was no difference in the number of ovulated oocytes (cumulus-oocyte complexes) obtained from the oviducts (D) of wild-type dams and Thy1.2-AMH'g dams on the first morning of estrus (Student's $t$-test, $n=8-10$, error bars=s.E.M.). Offspring derived from wild-type dams and Thy1.2-AMH'g studs ( $N=254)$ display the expected 1:1 Mendelian ratios in both Thy1.2-AMH genotype (E) and sex (F). A full color version of this figure is available at https://doi.org/10.1530/JOE-18-0005.

Zygote cleavage rates per pregnant female (Fig. 2H) and the number of 2-stage embryos that reached the morula stage or further were not significantly different between the two genotypes (Fig. 2I). However, significantly fewer embryos had developed to the blastocyst stage in Thy1.2-AMH ${ }^{\mathrm{Tg}}$ females compared to wild-type females (Fig. 1J). The embryos from Thy1.2-AMH ${ }^{\mathrm{Tg}}$ females also displayed a significantly higher incidence of morphological abnormalities (Table 1). Abnormal embryos were present in 7 of 12 Thy1.2-AMH ${ }^{\mathrm{Tg}}$ females but only 1 of 11 wildtype females. The effects of AMH overexpression appear to be indirect because embryos cultured from the zygote stage in the presence of recombinant $\mathrm{AMH}_{\mathrm{C}}$ have normal developmental progression (Fig. 2K) and normal cell numbers in the trophectoderm and inner cell mass (Supplementary Table 1 , see section on supplementary data given at the end of this article). The highest $\mathrm{AMH}_{\mathrm{C}}$ dose $(2 \mathrm{nmol} / \mathrm{L})$ is equivalent to circulating $\mathrm{AMH}$ concentrations in the Thy1.2-AMH ${ }^{\mathrm{Tg}}$ mice (McLennan et al. 2017).

Preimplantation embryo development is regulated by maternal production of growth factors and growth inhibitors. Transcripts for murine Amh mRNA and the AMH receptor subunits (Amhr2, Acvr1, Bmpr1a, Bmpr1b) were all detected in the oviducts at $35-37 \mathrm{~h}$ post-coitus
(Supplementary Table 2). We tested whether overexpression of AMH affects the expression of well-characterized growth promoters (Egf, Csf2, Il6, Pdgfa, Kitlg and Faah) and growth inhibitors (Csf1, Tnfsf10, Ifng). No significant differences were observed in the expression of any transcript between Thy1.2-AMH ${ }^{\mathrm{Tg}}$ and wild-type females (Supplementary Table 2) suggesting that AMH does not induce global changes in oviductal growth factor profiles.

AMH can modulate the hypothalamic neurons that regulate gonadotropin secretion (Cimino et al. 2016) and a severely defective hypothalamic-pituitary-gonadal axis in Thy1.2-AMH ${ }^{\mathrm{Tg}}$ was expected to affect estrus cycling. No significant difference was observed in the time-tocopulation of wild-type and Thy1.2-AMH ${ }^{\mathrm{Tg}}$ females when paired with male studs (Fig. 3A). Two of 10 Thy1.2-AMHrg females failed to get pregnant within 20 days of pairing, but became pregnant within 5 days when swapped to a new male. The mean estrus cycle length and the length of each stage as a proportion of the full cycle were not significantly different between the two genotypes (Fig. 3B and C). A single Thy1.2-AMH ${ }^{\mathrm{Tg}}$ female remained at the diestrus stage for 16 days and upon euthanasia her ovary was found to be abnormally small (see below). In early pregnancy, the rodent hypothalamus and pituitary orchestrate twice daily prolactin pulses that are needed 

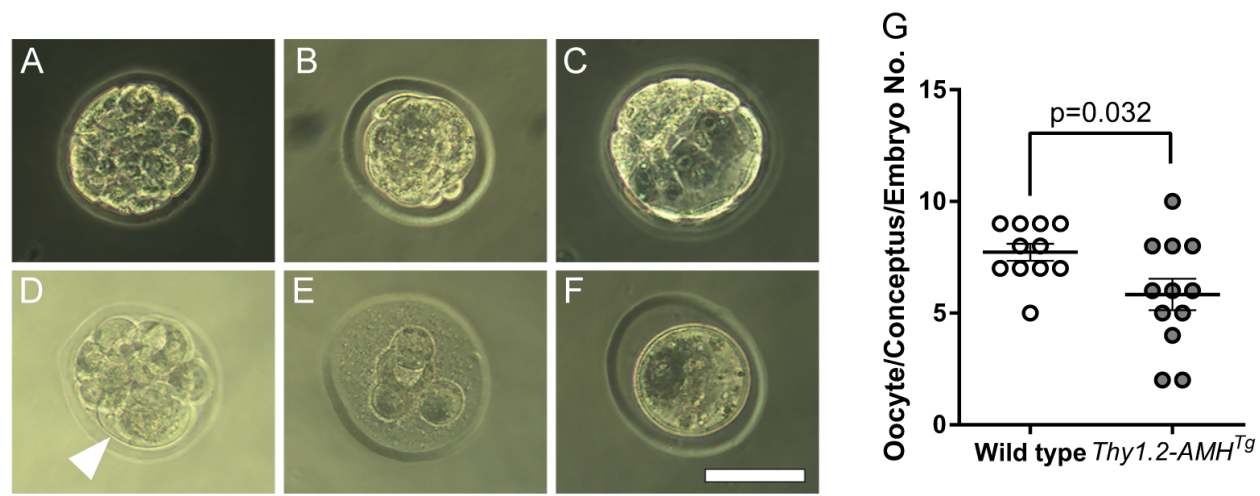

$\mathrm{H}$
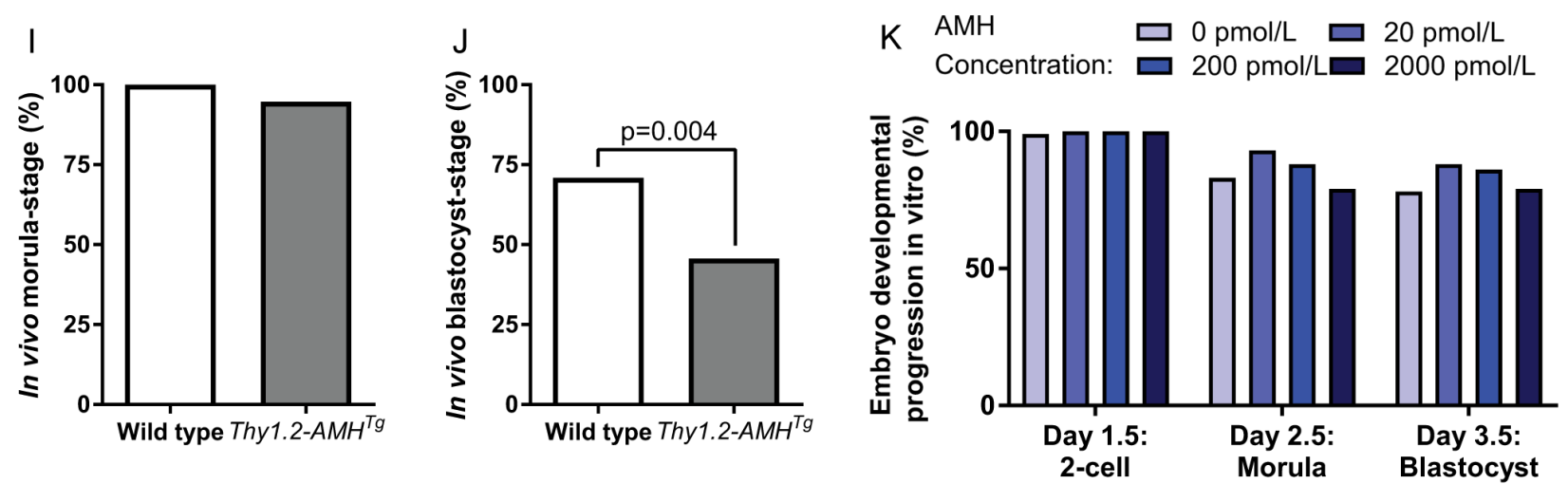

Figure 2

Delayed and abnormal development becomes evident in embryos from Thy1.2-AMH'g dams between the morula and blastocyst stage. The embryos flushed from wild-type and Thy1.2-AMHTg dams displayed a range of developmental stages at 3.25 days post-coitus, including morula (A), compacted morula (B) and blastocyst (C) stages. Abnormal forms were found in both genotypes, including embryos with asymmetric cell division (D, arrowhead) or cellular degeneration (E), often accompanied by developmental arrest. Single cell entities that could represent either unfertilized oocytes or growtharrested zygotes were also observed in both genotypes (F). The number of oocytes or concepti per dam was significantly lower (Student's $t$-test) in Thy 1.2-AMH ${ }^{\top 9}$ dams (G) but the percentage of oocytes that underwent the first cleavage per dam (H) was not significantly different between wild-type and Thy 1.2-AMHTg dams ( $P=0.313$, Student's $t$-test, $n=11-12$, error bars=s.E.M.). Of concepti from wild-type $(n=79)$ and Thy $1.2-A M H^{T} \mathrm{~g} / 0$ ( $(n=57)$ dams that reached the 2-cell stage or greater, the percentage that developed to the morula stage or greater by 3.25 days post-coitus (I) was not significantly different between the genotypes ( $P=0.071$, Fisher's exact test). However, significantly fewer Thy1.2-AMH ${ }^{\mathrm{T} g} / \mathrm{o}_{\text {-dam }}$ embryos reached the blastocyst stage than wild-type dam embryos (Fisher's exact test) by 3.25 days post-coitus (J). Recombinant AMH treatment had no significant effect on the development of cultured zygotes (K). Development was assessed by the number of embryos reaching the 2-cell stage by day 1.5, the morula stage by day 2.5 and the blastocyst stage by day 3.5 in vitro ( $n=80-81$, Pearson's chi-square test). A full color version of this figure is available at https://doi.org/10.1530/ JOE-18-0005.

to rescue the corpus luteum (Grattan et al. 2008). Serum prolactin levels were assessed $1 \mathrm{~h}$ before the darkness phase of the daily light cycle, when the diurnal peak is expected to occur. No significant difference was observed in prolactin levels between pregnant females of the two strains on day 2 of pregnancy (Fig. 3D). These preliminary experiments suggest that if AMH alters hypothalamic dysfunction, the effects are subtle.

Table 1 Abnormal embryo morphology in pregnant Thy1.2-AMH'g females.

Number of dams

Unfertilized oocytes/uncleaved zygoytes

Total embryo countc, d

Abnormal embryo count ${ }^{c, d}$

$\%$ Abnormalc

Number of dams with abnormal embryosc
Wild-type dams

11

6

79

4

5.1

$1(9.1 \%)$
Thy1.2-AMHTg dams

12

13

57

17

$29.8^{\mathrm{b}}$

$7\left(58.3 \%{ }^{a}\right)$

a $P<0.05$ compared to wild-type group, Fisher's exact test; ${ }^{b} P<0.001$ compared to wild-type group, Fisher's exact test; cincludes only the concepti/embryos that reached the 2-cell stage or greater; dmorphological abnormalities include; asymmetric cell division, failure to progress beyond the 8-cell stage and embryo degeneration commonly including reduced embryo size relative to the zona pellucida volume and an accumulation of cellular debris. 
A

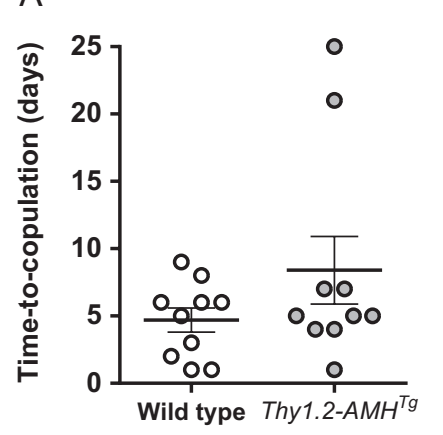

$B$

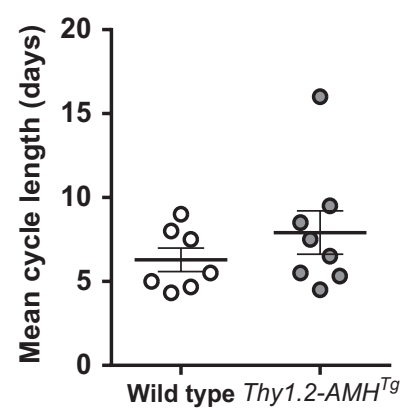

C
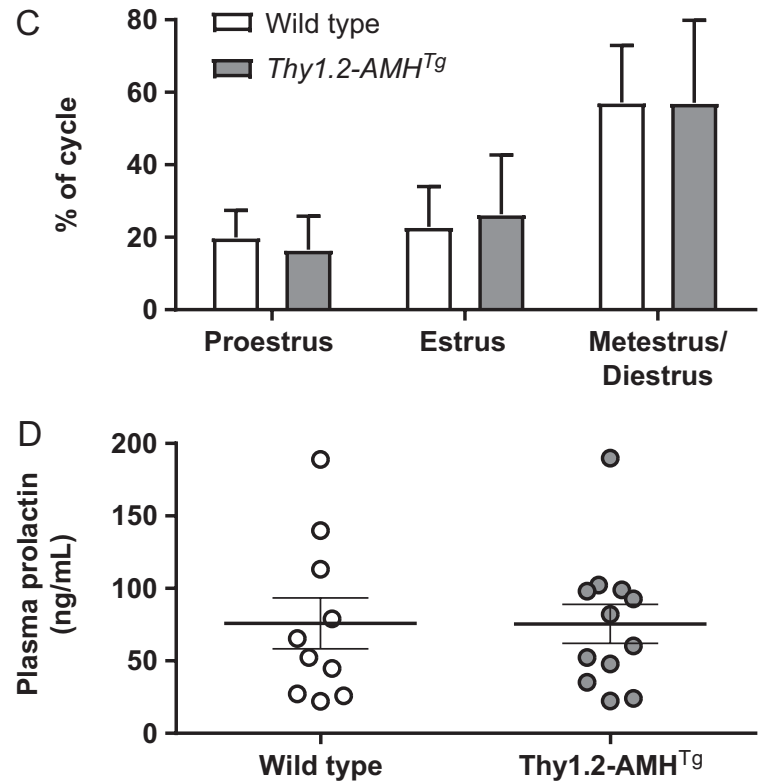

Figure 3

Estrous cycling and the stimulus to rescue the corpora lutea both appear to be functional in Thy1.2-AMH ${ }^{\mathrm{Tg}}$ female mice. The time-to-copulation for most Thy1.2-AMH'g females, determined by copulatory plugs, was within the range of the wild-type studs following pairing with stud males (A). No significant differences in mean estrous cycle length was observed between wild-type and Thy1.2-AMH'T females (B) with no differences in the relative lengths of the different cycle stages $(C, n=7-8$, error bars=S.E.M.). The percentage of the estrus cycle occupied by the different stages was not significantly different between the two genotypes (C). The diurnal surge in plasma prolactin on the second day of pregnancy (D) showed no significant difference between wild-type and Thy1.2-AMH ${ }^{\mathrm{T} g}$ females $(P=0.986$, Student's $t$-test, $n=10-12)$. Error bars $=$ S.E.M.

Histological examination of Thy1.2-AMHrg and wildtype ovaries collected immediately after puberty revealed the presence of developing follicles at all stages, but there were conspicuously fewer preantral follicles in Thy1.2$A M H^{\mathrm{Tg}}$ ovaries (Fig. $4 \mathrm{G}$ and $\mathrm{H}$ ). Most Thy1.2-AMH ${ }^{\mathrm{Tg}}$ ovaries had typical numbers of preovulatory follicles (Fig. 4F). Corpora lutea tissue from prior estrous cycles was present in most Thy1.2-AMH ${ }^{\mathrm{Tg}}$ females with the exception of one female that had few preovulatory follicles (Fig. 4I). Quantification of the different follicle classes revealed no differences in absolute numbers of primordial (Fig. 4A) or primary follicles (Fig. 4B). Primordial follicle counts are highly variable between females but correlate with the number of primary follicles (Richardson et al. 1987). When primary follicle numbers were standardized to primordial follicle counts a significant reduction in the relative rate of primordial follicle activation was detected in Thy1.2-AMH ${ }^{\mathrm{Tg}}$ female mice (Fig. 4C). An even larger reduction in preantral and small antral follicle numbers was present in the Thy1.2-AMH ${ }^{\mathrm{Tg}}$ ovaries relative to wildtype mice (Fig. 4D and E), but there was no significant difference in the number of preovulatory follicles (Fig. 4F). These data indicate that there is a moderate reduction in primary follicle counts in Thy1.2-AMH ${ }^{\mathrm{Tg}}$ mice relative to wild-type mice but a large reduction in follicle numbers immediately after the primary stage.

Ovaries from Thy1.2-AMH ${ }^{\mathrm{Tg}}$ and wild-type mice were examined at 5 months of age to determine if prolonged exposure to high levels of AMH leads to an accumulation of primordial follicles. Surprisingly, the numbers of primary and primordial follicles were significantly lower in Thy1.2-AMH ${ }^{\mathrm{Tg}}$ ovaries (Fig. 5A and B). There was no longer a difference in the ratio of primary to primordial follicles (Fig. 5C), but the large reduction in preantral and small antral follicles in Thy1.2-AMH ${ }^{\mathrm{Tg}}$ mice persisted (Fig. 5D and E). There was also a statistically significant reduction in the number of preovulatory follicles of Thy 1.2-AMH ${ }^{\mathrm{Tg}}$ ovaries relative to wild types at this time point (Fig. 5F).

\section{Discussion}

The Thy1.2-AMH' females exhibit severe subfertility caused by mid-gestational fetal resorption, with altered preimplantation embryo development. The delivery of transgenic AMH through the blood is likely to cause an elevation in AMH concentrations ovarian stroma, as there was a moderate inhibition of primordial follicle activation. The reduction of early preantral follicles was disproportionate to the reduction in primary follicle numbers suggesting that elevated AMH levels affect follicle survival at this stage. Young Thy1.2-AMH ${ }^{\mathrm{Tg}}$ females were still capable of ovulating similar numbers of oocytes to wild-type mice, but the delay in embryonic development might indicate that the developmental competence of the oocytes is impaired but other factors may contribute to the loss of embryos at the fetal stage (see below). 


\begin{tabular}{l|l|l|r|}
$\begin{array}{l}\text { Journal of } \\
\text { Endocrinology }\end{array}$ & $\begin{array}{l}\text { AMH overexpression and female } \\
\text { fertility }\end{array}$ & $\mathbf{2 3 7 : 2}$ \\
\hline
\end{tabular}
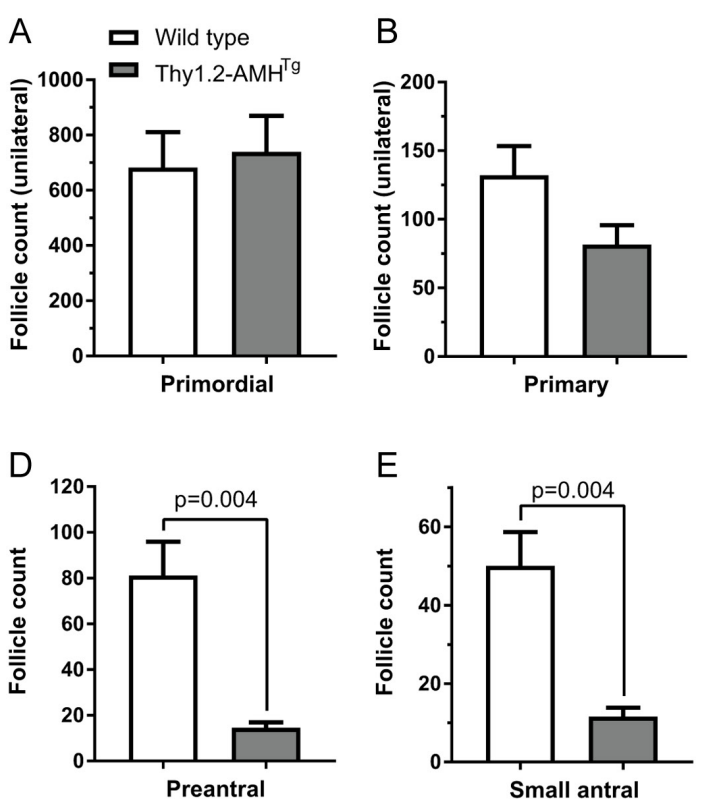

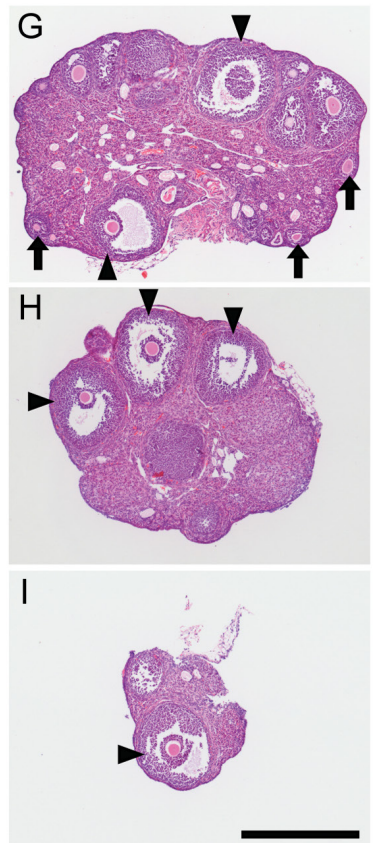

Figure 4

Ovarian follicle development is altered in Thy1.2-AMH'g female mice at 45-58 days of age. Unilateral primordial follicle (A) and primary follicle (B) counts were not significantly different in wild-type (white bars) and Thy1.2-AMH'g mouse ovaries. The ratio of primary follicles to primordial follicles per female was significantly lower in Thy 1.2-AMH'g female mice (C). Bilateral preantral follicle (D) and small antral follicle (E) counts were significantly lower in Thy1.2-AMH' females than in wild types. No significant differences were observed in bilateral preovulatory follicle counts (F). Histological sections from the center of wild-type $(\mathrm{G})$ and Thy1.2-AMHTg ovaries $(\mathrm{H}, \mathrm{I})$ reveal a large difference in the size of the ovaries. Large preovulatory follicles are present in the ovaries from both genotypes (arrowheads) but developing preantral follicles (arrows) are conspicuously absent in many sections from Thy 1.2-AMH'T ovaries. (Scale bar $=500 \mu \mathrm{m}, n=7$, error bars=s.E.M., Student's $t$-test.) A full color version of this figure is available at https://doi.org/10.1530/ JOE-18-0005.

The majority of the follicle loss in Thy1.2-AMH ${ }^{\mathrm{Tg}}$ mice occurred in the early preantral follicle stage, with little additional attrition at subsequent stages. Larger follicles may be less susceptible because they have greater sensitivity to the survival-promoting effects of FSH (Abel et al. 2000). A reduction in AMHR2 expression in the later antral stages (Baarends et al. 1995) may also protect the larger follicles. $\mathrm{Amh}^{-1-}$ mice have greater rates of primordial
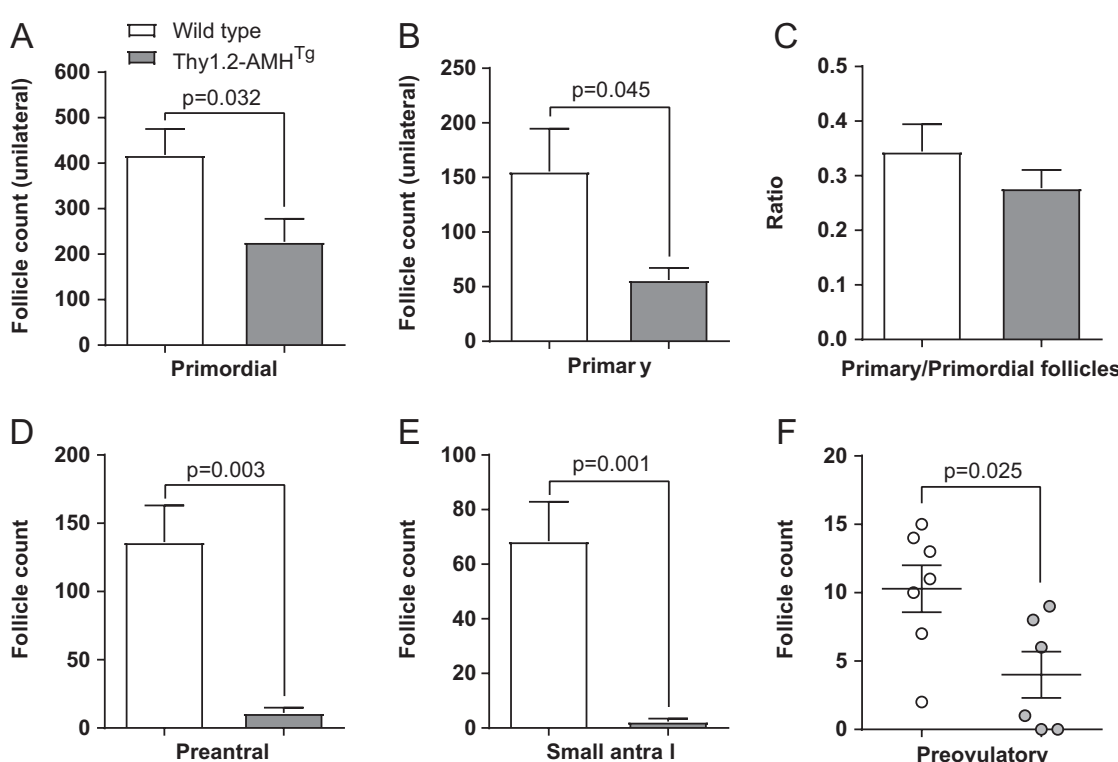

E

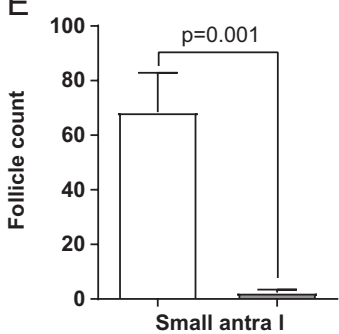

Figure 5

Ovarian follicle development is altered in Thy 1.2-AMH'g female mice at 150-162 days of age. Unilateral primordial follicle $(A)$ and primary follicle counts (B) were significantly lower in the Thy 1.2-AMH'g female mice. No difference $(P=0.303)$ was observed in the ratio of primary follicles to primordial follicles per female (C). Reduced bilateral preantral (D), small antral (E) and preovulatory (F) follicle counts were observed in the Thy1.2-AMH'g females relative to wild-type controls. $(n=6-7$, error bars $=$ s.E.M., Student's $t$-test.) 
follicle activation and larger developing follicle pools than $\mathrm{Amh}^{+/+}$mice (Durlinger et al. 1999) but the number of preovulatory follicles is unaffected (Visser et al. 2007). This is likely due to the strong overriding influence of the hypothalamic-pituitary gonadal axis on the regulation of ovulation. One hypothesis is that acquisition of greater sensitivity to FSH may be capable of protecting antral follicles from the influence of AMH. Few follicles make it to the antral stage in the Thy1.2-AMH Trg mice but a high proportion of these follicles survive to ovulation. Another hypothesis is that the developmental increases in follicle expression of gremlin 1 and 2 (Kristensen et al. 2014, Nilsson et al. 2014) may also protect larger follicles, as these AMH-binding proteins neutralize the effects of AMH (Nilsson et al. 2014). Additional unidentified processes may also contribute to the survival of larger follicles when AMH levels are elevated.

Early antral follicles typically express less AMH than late preantral and small antral follicles (Weenen et al. 2004); hence, granulosa cells in early antral follicles may be incapable of high AMH-output. However, the present study raises the possibility that AMH induces early antral follicle atresia, in which case high-output follicles may be rapidly removed from the developing population. Our initial observations suggested that Thy1.2-AMH ${ }^{\mathrm{Tg}}$ mouse late preantral and small antral follicles express normal levels of $\mathrm{AMH}$, but $\mathrm{AMH}$ was not detectable in primary and early secondary follicles (McLennan et al. 2017). This may represent a compensatory mechanism or it may be that only follicles with low endogenous expression can survive the transgenic overexpression of AMH. This may have particular relevance in pathological conditions such as polycystic ovary syndrome, where follicular fluid and serum AMH levels are often elevated (Pellatt et al. 2007).

The reduced primordial follicle counts in 5-monthold Thy1.2-AMH ${ }^{\mathrm{Tg}}$ mice was surprising, as numerous in vitro studies have demonstrated that short-term AMH treatment (2-10 days) inhibits primordial follicle activation in ovary explant cultures (Durlinger et al. 2002, Carlsson et al. 2006, Nilsson et al. 2007, Rocha et al. 2016). However, 4 weeks of AMH treatment has been shown to increase primordial activation rates (Schmidt et al. 2005); hence, the effect of AMH may change with the length of exposure. Alternatively, the collapse of the primordial follicle population may be indirect and subsequent to the profound effects on the developing follicle population. However, the possibility that prolonged elevation in $\mathrm{AMH}$ is toxic to dormant primordial follicles requires urgent investigation because AMH treatment has been proposed as a reversible contraceptive and a therapeutic inhibitor of ovarian reserve depletion (Margolskee \& Selgrade 2013, Hayes et al. 2016, Kong et al. 2016, Kano et al. 2017). The loss of primordial follicles is thought to be irreversible and the 5-month-old Thy1.2-AMH ${ }^{\mathrm{Tg}}$ phenotype indicates that more research is needed to determine the safety of longterm AMH treatment.

It is not yet clear whether the Thy1.2-AMH ${ }^{\mathrm{Tg}}$ ovarian phenotype is related to the subfertility phenotype. The phenotype is consistent with the limited oocyte pool hypothesis, which proposes that a small developing follicle pool imparts reduced negative feedback on the pituitary and hypothalamus leading to increased FSH secretion, accelerated antral follicle development and ovulation of immature oocytes (Warburton 1989). The phenotype is also consistent with an alternative hypothesis proposing that larger developing follicle pools enable greater capacity to select follicles with high-quality oocytes, while excluding oocytes of low-quality (Pankhurst 2017). However, AMH in the hypothalamus can modulate gonadotropin secretion (Cimino et al. 2016), and there is scope for the neuronal AMH expression to affect this system, with downstream effects on reproduction. Similarly, AMHR2 has been detected in the endometrium and placenta (Renaud et al. 2005, Wang et al. 2009, Novembri et al. 2015), which raises the possibility that AMH acts directly on the uterus or placenta to induce fetal resorption independently of the ovarian effects. The upregulation of AMHR2 expression in uterine endometrium during pregnancy (Renaud et al. 2005) suggests that sensitivity to AMH increases in this organ during pregnancy.

We propose three hypothetical mechanisms of fetal loss in the Thy1.2-AMH ${ }^{\mathrm{Tg}}$ females; (1) uterine rejection of the fetus, (2) failure of endocrine support of pregnancy from the hypothalamic-pituitary-gonadal axis and/or (3) poor initial oocyte quality, affecting subsequent embryonic and fetal development. The loss of oocytes and concepti at different stages may arise due to a combination of multiple mechanisms acting at different stages. Alternatively, elevated AMH levels may have a single action with varied effects on oocytes or concepti from Thy1.2-AMH $H^{\mathrm{Tg}}$ dams. Such variation could explain why some concepti survive longer than others but our prior experiments indicate that few will survive to birth (McLennan et al. 2017).

\section{Conclusion}

Very high levels of AMH affect fertility by shutting down primordial follicle activation (Kano et al. 
2017). The lower levels of AMH in the circulation of Thy1.2-AMH ${ }^{\mathrm{Tg}}$ mice permit primordial follicle activation but still lead to severe subfertility. A large absence of early preantral follicles appears to indicate that this follicle stage is most susceptible to the effects of moderate AMH overexpression. Serum AMH levels naturally show a large degree of variation between individuals; hence, it will be important to determine whether the Thy1.2-AMH ${ }^{\mathrm{Tg}}$ phenotype recapitulates a biological phenomenon or is more relevant to pharmacological doses of AMH.

\section{Supplementary data}

This is linked to the online version of the paper at https://doi.org/10.1530/ JOE-18-0005.

\section{Declaration of interest}

The authors declare that there is no conflict of interest that could be perceived as prejudicing the impartiality of the research reported.

\section{Funding}

This research was funded by the Health Research Council of New Zealand (grant number: 14-441) and a Society for Reproductive Biology Early Career Researcher Collaborative Research Travel Award.

\section{Acknowledgements}

The authors would like to thank Dr I S McLennan and A/Prof. C L Jasoni for their guidance and advice and B Leathart, Dr R S Brown, Dr P Gustafson and Prof. D R Grattan for technical assistance and advice. Prof. D K Gardner is thanked for the provision of experimental reagents and materials.

\section{References}

Abel MH, Wootton AN, Wilkins V, Huhtaniemi I, Knight PG \& Charlton HM 2000 The effect of a null mutation in the folliclestimulating hormone receptor gene on mouse reproduction. Endocrinology 141 1795-1803. (https://doi.org/10.1210/ endo.141.5.7456)

Baarends WM, Uilenbroek JT, Kramer P, Hoogerbrugge JW, van Leeuwen EC, Themmen AP \& Grootegoed JA 1995 Anti-mullerian hormone and anti-mullerian hormone type II receptor messenger ribonucleic acid expression in rat ovaries during postnatal development, the estrous cycle, and gonadotropin-induced follicle growth. Endocrinology 136 4951-4962. (https://doi.org/10.1210/ endo.136.11.7588229)

Brown RS, Kokay IC, Herbison AE \& Grattan DR 2010 Distribution of prolactin-responsive neurons in the mouse forebrain. Journal of Comparative Neurology 518 92-102. (https://doi.org/10.1002/ cne.22208)

Carlsson IB, Scott JE, Visser JA, Ritvos O, Themmen AP \& Hovatta O 2006 Anti-Mullerian hormone inhibits initiation of growth of human primordial ovarian follicles in vitro. Human Reproduction $\mathbf{2 1}$ 2223-2227. (https://doi.org/10.1093/humrep/del165)

Cimino I, Casoni F, Liu X, Messina A, Parkash J, Jamin SP, CatteauJonard S, Collier F, Baroncini M, Dewailly D, et al. 2016 Novel role for anti-Mullerian hormone in the regulation of GnRH neuron excitability and hormone secretion. Nature Communications 710055. (https://doi.org/10.1038/ncomms10055)

Depmann M, Faddy MJ, van der Schouw YT, Peeters PH, Broer SL, Kelsey TW, Nelson SM \& Broekmans FJ 2015 The relationship between variation in size of the primordial follicle pool and age at natural menopause. Journal of Clinical Endocrinology and Metabolism 100 E845-E851. (https://doi.org/10.1210/jc.2015-1298)

Durlinger AL, Kramer P, Karels B, de Jong FH, Uilenbroek JT, Grootegoed JA \& Themmen AP 1999 Control of primordial follicle recruitment by anti-Mullerian hormone in the mouse ovary. Endocrinology 140 5789-5796. (https://doi.org/10.1210/ endo.140.12.7204)

Durlinger AL, Gruijters MJ, Kramer P, Karels B, Ingraham HA, Nachtigal MW, Uilenbroek JT, Grootegoed JA \& Themmen AP 2002 Anti-Mullerian hormone inhibits initiation of primordial follicle growth in the mouse ovary. Endocrinology 143 1076-1084. (https:// doi.org/10.1210/endo.143.3.8691)

Faddy MJ, Gosden RG, Gougeon A, Richardson SJ \& Nelson JF 1992 Accelerated disappearance of ovarian follicles in mid-life: implications for forecasting menopause. Human Reproduction 7 1342-1346. (https://doi.org/10.1093/oxfordjournals.humrep.a137570)

Gardner DK \& Lane M 2007 Embryo culture systems. In In Vitro Fertilization: A Practical Approach, pp 221-282. Ed DK Gardner. New York, NY, USA: Informa Healthcare.

Gardner DK \& Lane M 2014 Mammalian preimplantation embryo culture. Methods in Molecular Biology 1092 167-182. (https://doi. org/10.1007/978-1-60327-292-6_11)

Grattan DR, Steyn FJ, Kokay IC, Anderson GM \& Bunn SJ 2008 Pregnancy-induced adaptation in the neuroendocrine control of prolactin secretion. Journal of Neuroendocrinology 20 497-507. (https:// doi.org/10.1111/j.1365-2826.2008.01661.x)

Hayes E, Kushnir V, Ma X, Biswas A, Prizant H, Gleicher N \& Sen A 2016 Intra-cellular mechanism of Anti-Mullerian hormone (AMH) in regulation of follicular development. Molecular and Cellular Endocrinology 433 56-65. (https://doi.org/10.1016/j.mce.2016.05.019)

Jeppesen JV, Anderson RA, Kelsey TW, Christiansen SL, Kristensen SG, Jayaprakasan K, Raine-Fenning N, Campbell BK \& Yding Andersen C 2013 Which follicles make the most anti-Mullerian hormone in humans? Evidence for an abrupt decline in AMH production at the time of follicle selection. Molecular Human Reproduction 19 519-527. (https://doi.org/10.1093/molehr/gat024)

Kano M, Sosulski AE, Zhang L, Saatcioglu HD, Wang D, Nagykery N, Sabatini ME, Gao G, Donahoe PK \& Pepin D 2017 AMH/MIS as a contraceptive that protects the ovarian reserve during chemotherapy. PNAS 114 E1688-E1697. (https://doi.org/10.1073/pnas.1620729114)

Kaufman MH 1992 The Atlas of Mouse Development. London, UK: Academic Press.

Kevenaar ME, Meerasahib MF, Kramer P, van de Lang-Born BM, de Jong FH, Groome NP, Themmen AP \& Visser JA 2006 Serum antimullerian hormone levels reflect the size of the primordial follicle pool in mice. Endocrinology 147 3228-3234. (https://doi.org/10.1210/ en.2005-1588)

Kong HS, Kim SK, Lee J, Youm HW, Lee JR, Suh CS \& Kim SH 2016 Effect of exogenous anti-Mullerian hormone treatment on cryopreserved and transplanted mouse ovaries. Reproductive Sciences 23 51-60. (https://doi.org/10.1177/1933719115594021)

Kristensen SG, Andersen K, Clement CA, Franks S, Hardy K \& Andersen CY 2014 Expression of TGF-beta superfamily growth factors, their receptors, the associated SMADs and antagonists in five isolated size-matched populations of pre-antral follicles from normal human http://joe.endocrinology-journals.org https://doi.org/10.1530/JOE-18-0005 (c) 2018 Society for Endocrinology Published by Bioscientifica Ltd. Printed in Great Britain 
ovaries. Molecular Human Reproduction 20 293-308. (https://doi. org/10.1093/molehr/gat089)

Margolskee A \& Selgrade JF 2013 A lifelong model for the female reproductive cycle with an antimullerian hormone treatment to delay menopause. Journal of Theoretical Biology 326 21-35. (https://doi. org/10.1016/j.jtbi.2013.02.007)

McGee EA \& Hsueh AJ 2000 Initial and cyclic recruitment of ovarian follicles. Endocrine Reviews 21 200-214. (https://doi.org/10.1210/ edrv.21.2.0394)

McLennan IS, Koishi K, Batchelor NJ \& Pankhurst MW 2017 Mice with either diminished or elevated levels of anti-Müllerian hormone (AMH) have decreased litter sizes. Biology of Reproduction 98 54-62. (https://doi.org/10.1093/biolre/iox151)

Monniaux D, Clement F, Dalbies-Tran R, Estienne A, Fabre S, Mansanet C \& Monget P 2014 The ovarian reserve of primordial follicles and the dynamic reserve of antral growing follicles: what is the link? Biology of Reproduction 90 85. (https://doi.org/10.1095/biolreprod.113.117077)

Myers M, Britt KL, Wreford NG, Ebling FJ \& Kerr JB 2004 Methods for quantifying follicular numbers within the mouse ovary. Reproduction 127 569-580. (https://doi.org/10.1530/rep.1.00095)

Nilsson E, Rogers N \& Skinner MK 2007 Actions of anti-Mullerian hormone on the ovarian transcriptome to inhibit primordial to primary follicle transition. Reproduction 134 209-221. (https://doi. org/10.1530/REP-07-0119)

Nilsson EE, Larsen G \& Skinner MK 2014 Roles of Gremlin 1 and Gremlin 2 in regulating ovarian primordial to primary follicle transition. Reproduction 147 865-874. (https://doi.org/10.1530/REP-14-0005)

Novembri R, Funghi L, Voltolini C, Belmonte G, Vannuccini S, Torricelli M \& Petraglia F 2015 Placenta expresses anti-Mullerian hormone and its receptor: sex-related difference in fetal membranes. Placenta 36 731-737. (https://doi.org/10.1016/j. placenta.2015.04.009)

Oorschot DE 1994 Are you using neuronal densities, synaptic densities or neurochemical densities as your definitive data? There is a better way to go. Progress in Neurobiology 44 233-247. (https://doi. org/10.1016/0301-0082(94)90040-X)

Pankhurst MW 2017 A putative role for anti-Mullerian hormone (AMH) in optimising ovarian reserve expenditure. Journal of Endocrinology 233 R1-R13. (https://doi.org/10.1530/JOE-16-0522)

Pankhurst MW, Leathart BL, Batchelor NJ \& McLennan IS 2016 The anti-Mullerian hormone precursor (proAMH) is not converted to the receptor-competent form (AMHN,C) in the circulating blood of mice. Endocrinology 157 1622-1629. (https://doi.org/10.1210/en.20151834)

Pellatt L, Hanna L, Brincat M, Galea R, Brain H, Whitehead S \& Mason H 2007Granulosa cell production of anti-Mullerian hormone is increased in polycystic ovaries. Journal of Clinical Endocrinology Metabolism 92 240-245. (https://doi.org/10.1210/jc.2006-1582)

Renaud EJ, MacLaughlin DT, Oliva E, Rueda BR \& Donahoe PK 2005 Endometrial cancer is a receptor-mediated target for Mullerian Inhibiting Substance. PNAS 102 111-116. (https://doi.org/10.1073/ pnas.0407772101)

Richardson SJ, Senikas V \& Nelson JF 1987 Follicular depletion during the menopausal transition: evidence for accelerated loss and ultimate exhaustion. Journal of Clinical Endocrinology Metabolism 65 1231-1237. (https://doi.org/10.1210/jcem-65-6-1231)

Rocha R, Lima LF, Carvalho AA, Chaves RN, Bernuci MP, Rosa ESA, Rodrigues A, Campello CC \& Figueiredo JR 2016 Immunolocalization of the anti-Mullerian hormone (AMH) in caprine follicles and the effects of amh on in vitro culture of caprine pre-antral follicles enclosed in ovarian tissue. Reproduction in Domestic Animals $\mathbf{5 1}$ 212-219. (https://doi.org/10.1111/rda.12668)

Schmidt KL, Kryger-Baggesen N, Byskov AG \& Andersen CY 2005 AntiMullerian hormone initiates growth of human primordial follicles in vitro. Molecular and Cellular Endocrinology 234 87-93. (https://doi. org/10.1016/j.mce.2004.12.010)

Visser JA \& Themmen AP 2014 Role of anti-Mullerian hormone and bone morphogenetic proteins in the regulation of FSH sensitivity. Molecular and Cellular Endocrinology 382 460-465. (https://doi.org/10.1016/j. mce.2013.08.012)

Visser JA, Durlinger AL, Peters IJ, van den Heuvel ER, Rose UM, Kramer P, de Jong FH \& Themmen AP 2007 Increased oocyte degeneration and follicular atresia during the estrous cycle in anti-Mullerian hormone null mice. Endocrinology 148 2301-2308. (https://doi.org/10.1210/ en.2006-1265)

Wang J, Dicken C, Lustbader JW \& Tortoriello DV 2009 Evidence for a Mullerian-inhibiting substance autocrine/paracrine system in adult human endometrium. Fertility and Sterility 91 1195-1203. (https://doi. org/10.1016/j.fertnstert.2008.01.028)

Warburton D 1989 The effect of maternal age on the frequency of trisomy: change in meiosis or in utero selection? Progress in Clinical and Biological Research 311 165-181.

Weenen C, Laven JS, Von Bergh AR, Cranfield M, Groome NP, Visser JA, Kramer P, Fauser BC \& Themmen AP 2004 Anti-Mullerian hormone expression pattern in the human ovary: potential implications for initial and cyclic follicle recruitment. Molecular Human Reproduction 10 77-83. (https://doi.org/10.1093/molehr/gah015)

Xu J, Bishop CV, Lawson MS, Park BS \& Xu F 2016 Anti-Mullerian hormone promotes pre-antral follicle growth, but inhibits antral follicle maturation and dominant follicle selection in primates. Human Reproduction 31 1522-1530. (https://doi.org/10.1093/humrep/ dew100)

Received in final form 27 February 2018

Accepted 14 March 2018

Accepted Preprint published online 14 March 2018 http://joe.endocrinology-journals.org https://doi.org/10.1530/JOE-18-0005 (c) 2018 Society for Endocrinology Published by Bioscientifica Ltd. Printed in Great Britain 